ecchymoses or haematuria), and liquorice sweets (to induce oedema). One such patient complaining of intractable diarrhoea disguised her magnesium sulphate crystals as bathsalts and kept them in an appropriately decorated glass jar in the ward bathroom. Not surprisingly this was not discovered when her locker was searched during her deliberately protracted absence in the $x$ ray department. Her stocks were regularly replenished by kind, unsuspecting innocent friends, who were requested to bring Epsom salts rather than flowers when they visited her. Such patients are evasive, secretive, and curiously unconcerned by their presenting symptoms; their relations with the ward staff are politely faultless but usually cold and withdrawn.

Dermatitis artefacta, so familiar to dermatologists and to surgeons whose patients' wounds do not heal, is a major problem and may be the cause, incomprehensible to the doctor, of the amputation of fingers, a hand, or an arm. Almost all such patients are women and aged less than $30 .^{5}$ The unsophisticated may induce "unbiological" lesions of bizarre shape with linear or geometric outline, but those with medical knowledge can produce lesions in seemingly inaccessible sites and mimic closely naturally occurring conditions. Acids, alkalis, phenol, and heated needles and scalpels are the common instruments. Other patients induce extensive bruises, and some use rubber bands or tourniquets to produce chronic oedema of a hand or leg.

One of the most surprising group of deceivers is the parent who induces factitious illness in an (apparently) much loved child. This activity may range from a mother who records a spurious fever to one who visits her septicaemic child every afternoon in hospital and introduces bacterial contaminants into the antibiotic infusion line so that the child's temperature spikes two hours after her departure.

With the exception of those with Munchausen's syndrome, other types of deceivers engender much sympathy. Members of the family are supportive and become critical of the doctors who fail to effect a cure. ${ }^{6}$ In hospital the patient may enlist the support of a favourite nurse. Any suggestion-before the evidence is incontrovertible-that the problem is self induced usually leads to a prompt change of medical attendant..$^{56}$

The management of such patients is never easy. Direct confrontation of the patient or the relatives is often considered disastrous, ${ }^{5}$ largely because it is seen as a rejection by the patient and the doctor. Indeed, many doctors fear a confrontation in the belief that it will lead to "psychological decompensation, flight, rage, or suicide."3 To judge by reported experience such is not the case-provided that a therapeutic vacuum is not produced, that accusatory or condemnatory attitudes are avoided, and that there is a firm promise of continued supervision and support. These patients are seldom malingerers. The purpose of or gain from their factitious illness is often hard to discern. Often the deceivers are immature, sexually inhibited or frightened, and seek companionship and caring attention. A large number of non-specific terms such as "borderline" personality disorder have been used to describe these patients, but psychoses are rare. Quite often, before the diagnosis is firmly established, an experienced psychiatrist will declare the patient as perfectly normal and unquestionably suffering from organic disease. Once recognised, the prognosis is surprisingly good, and probably many cases are missed because the "illness" may not be as protracted as published examples suggest.

R I S BAYLISS
1 Asher R. Munchausen's syndrome. Lancet 1951 ; i:339-41.

2 Pallis CA, Bamji AN. McIlroy was here. Or was he? Br Med $\mathcal{F} 1979$;i: 973-5.

${ }^{3}$ Reich P, Gottfried LA. Factitious disorders in a teaching hospital. Ann Intern Med 1983;99:240-7.

4 Aduan RP, Fauci AS, Dale DC, Herzberg JH, Wolff SM. Factitious fever and self-induced infection. A report of 32 cases and review of the literature. Ann Intern Med 1979;90:230-42.

${ }^{5}$ Sneddon IB. Simulated disease: problems in diagnosis and management. The Parkes Weber lecture 1982. F $R$ Coll Physicians Lond 1983;17: 199-205.

${ }^{6}$ Naish JM. Problems of deception in medical practice. Lancet 1979;ii: 139-42.

\section{Alcoholic myopathy}

The harmful effects of alcohol on the human body have long been known, although the enthusiasm of the medical profession for proselytising in public about these has varied over the years. Currently it is at a high pitch, for the damage is now known to be due to a direct toxic effect of ethyl alcohol, which is dose dependent.

The toxic effects of alcohol on the liver and the nervous system are well known and recognised with increasing frequency in Britain. ${ }^{1}$ Alcoholic myopathy, by contrast, in either acute or chronic forms has hitherto been regarded as rare. For example, only eight patients complained of muscle weakness (as opposed to neuropathic symptoms) in a detailed study of the presenting features of 510 patients with alcoholic liver disease in the north east of England and Scotland. ${ }^{1}$ Slavin et al, however, have recently drawn attention to the fact that patients who drink over $100 \mathrm{~g}$ of ethanol a day for at least three years may develop a reversible and selective atrophy of type 2B fibres. ${ }^{2}$ They also found histochemical and ultrastructural evidence of accumulation of lipids in the muscles from eight of their patients. ${ }^{3}$ Quantitative analysis showed that this was due to an accumulation of triglycerides.

Asked about alcohol and the muscles, most doctors would focus on the acute rhabdomyolytic crisis which occurs in chronic alcoholics after a sustained bout of heavy drinking. ${ }^{4}$ These patients develop swollen, extremely painful, and exquisitely tender muscles with severe proximal weakness. Acute renal failure requiring short term dialysis may complicate the condition, though spontaneous recovery is the rule rather than the exception-provided of course that the patient withdraws from alcohol successfully. The pathogenesis of the acute myonecrosis is unknown; it may be a direct toxic effect of alcohol on the muscle cell or it may be an idiosyncratic reaction similar to that seen in heroin addicts. Ekbom et al have distinguished acute and subacute or chronic forms of alcoholic myopathy, which remit spontaneously in a few months if withdrawal is successful. ${ }^{5} \mathrm{~A}$ subclinical myopathy has been reported in chronic alcoholics, ${ }^{6}$ although Faris and Reyes thought that the muscle lesion in these patients was more likely to be neurogenic than myopathic. ${ }^{\text {? }}$

The pathophysiological basis for skeletal muscle degeneration in chronic alcoholism is unknown. Perkoff, Hardy, and Velez-Garcia reported impaired production of lactate after ischaemic exercise within 48 hours of intoxication in a group of alcoholics. They also found that muscle phosphorylase activity was low or in the low normal range in six of seven biopsy specimens from these patients. ${ }^{8}$ Nevertheless, glycolytic enzyme activity tends to be reduced in a variety of necrobiotic myopathies, ${ }^{9}$ so this finding is probably non-specific. Similarly, the observation that chronic alcoholics develop selective 
atrophy of type $2 \mathrm{~B}$ fibres ${ }^{2}$ is probably non-specific in view of the many pathological conditions in which it develops (though the point is well made that it is not simply a consequence of immobilisation). ${ }^{10}$

Nevertheless, the putative abnormality of triglyceride metabolism in skeletal muscle reported by Sunnasy and colleagues is of interest and merits detailed exploration. ${ }^{3}$ In spite of the obvious analogy with the fatty liver of chronic alcoholism, increased synthesis of triglyceride is unlikely to be the explanation (there is no evidence that this occurs in skeletal muscle). In addition, Martin et al have shown that some aspects of mitochondrial function are normal in alcoholic myopathy, ${ }^{11}$ notwithstanding the morphological abnormalities which may occur in muscle mitochondria. ${ }^{12}$ Further data on lipid metabolism in the muscles of patients with alcoholic myopathy are awaited with interest. Meanwhile we can take encouragement from the fact that effective withdrawal from alcohol will usually be followed by improvement in muscle strength.

P HUdGSON

Consultant Neurologist,

Regional Neurological Centre,

Newcastle General Hospital,

Newcastle upon Tyne NE4 6BE

Hislop WS, Bouchier IAS, Allan JG, et al. Alcoholic liver disease in Scotland and northeastern England: presenting features in 510 patients. Qf Med 1983;52:232-43.

Slavin G, Martin F, Ward P, Levi J, Peters T. Chronic alcohol excess is associated with selective but reversible injury to type $2 \mathrm{~B}$ muscle fibres. 7 Clin Pathol 1983;36:772-7.

${ }^{3}$ Sunnasy D, Cairns SR, Martin F, Slavin G, Peters TJ. Chronic alcoholic skeletal muscle myopathy: a clinical histological and biochemical assessment of muscle lipid. 7 Clin Pathol 1983;36:778-84.

1 Hed R, Larsson H, Wahlgren F. Acute myoglobinuria. Report of a case with a fatal outcome. Acta Med Scand 1955;152:459-63.

' Ekbom K, Hed R, Hussein L, Kirstein L, Astrom K-E. Muscular affections in chronic alcoholism. Arch Neurol 1964;10:449-58.

${ }^{6}$ Perkoff GT. Alcoholic myopathy. Annu Rev Med $1971 ; 22: 125-32$.

7 Faris AA, Reyes MG. Reappraisal of alcoholic myopathy. Clinical and biopsy study on chronic alcoholics without muscle weakness or wasting. 7 Neurol Neurosurg Psychiatry $1971 ; 34: 86-92$

* Perkoff GT, Hardy P, Velez-Garcia E. Reversible acute muscular syndrome in chronic alcoholism. N Engl f Med 1966;274:1277-85.

${ }^{9}$ Pennington RJT. Biochemical aspects of muscle disease. In: Walton JN, ed. Disorders of voluntary muscle. 4 th ed. Edinburgh: Churchill Livingstone, $1981: 417-47$

1 " Haggmark T, Eriksson E. Cylinder or mobile cast brace after knee ligament surgery. A clinical analysis and morphological and enzymatic studies of changes in the quadriceps muscle. Am 7 Sports Med 1979;7:48-56.

'Martin FC, Levi AJ, Slavin G, Peters TJ. The selective reversible myopathy of alcoholism. Eur $\mathcal{F}$ Clin Invest 1982;12:153.

12 Klinkerfuss G, Bleisch V, Dioso MM, Perkhoff GT. A spectrum of myopathy associated with alcoholism. II. Light and electron microscopic observations. Ann Intern Med 1967;67:493-510.

\section{Chemotherapy of solid tumours : trials and tribulations}

The selection of patients most likely to benefit from cancer chemotherapy is one of the most difficult yet most important tasks for the clinical oncologist. In each case the problems of drug toxicity and expense must be balanced against the likely effect on the tumour-and so on the patient's symptoms and life expectation. Few would argue with the use of toxic drug combinations to treat young men with metastatic testicular teratoma, most of whom are likely to be cured, and the gains from chemotherapy of the lymphomas and some solid tumours such as ovarian and small cell lung cancer are equally readily apparent.

Unfortunately, however, many of the solid tumours are relatively insensitive to chemotherapy. Responses are seen, and the "response rates" for individual drugs and drug combinations are known, but the impact on survival of a limited reduction in tumour volume remains unclear. ${ }^{1}$ Placebo controlled clinical trials are rare in this setting. The problems and pitfalls associated with the chemotherapy of many solid tumours are well exemplified by recent studies in patients with recurrent or advanced squamous cell carcinoma of the head and neck region.

Chemotherapy has been used in patients with these cancers both for recurrent disease after primary treatment and for bulky, poor prognosis tumours at presentation. ${ }^{2}$ Early clinical trials showed that intravenous methotrexate, given at low dose, was the most effective chemotherapy for these patients. ${ }^{2}$ Despite optimal treatment, however, the response rate was only $30^{\circ} \%$ and regression of the tumour was often short lived. Different approaches were therefore needed, and the 1970s saw the evaluation of several new drugs such as cisplatin and also new methods of administration such as high dose methotrexate with folinic acid "rescue." The expense and potential toxicities of these regimens were given little attention in the initial assessment, and they were rapidly incorporated into treatment on largely inadequate grounds. More recently it has become clear that neither cisplatin ${ }^{3}$ nor high dose methotrexate $^{4}$ offers appreciable benefits over the traditional treatment with low dose methotrexate. Nor do drug combinations offer any substantial benefit over single agents. ${ }^{56}$ Drug schedules which are "kinetically" designed" offer no additional benefit and have not given reproducible results, ${ }^{8}$ though their use is widespread in Britain.

Tragically, many patients with squamous cell carcinoma of the head and neck present with locally extensive or regionally metastatic disease and so have a poor prognosis. Furthermore, the morbidity associated with wide field irradiation or chemotherapy or both may be severe. Chemotherapy given as first treatment is sometimes highly effective initially: it may sterilise the tumour and enable smaller treatment fields to be used. ${ }^{9}$ After several encouraging but uncontrolled pilot studies combining single drug chemotherapy and radiotherapy large controlled trials were set up. The results were mainly negative. ${ }^{2}$ None the less, similar enthusiasm is now expressed for combination chemotherapy together with radiotherapy, and multiple reports of uncontrolled trials have appeared advocating this treatment. ${ }^{21011}$ Again, however, a well controlled trial using radiotherapy and combination chemotherapy in a "kinetically" designed schedule failed to show any benefit-in striking contrast to previous, uncontrolled studies. ${ }^{12}$ This study should sound a cautionary note. Combination chemotherapy and radiotherapy are certain to be more toxic than either treatment alone, and on this (limited) evidence they are not indicated in routine practice. The role of combined modality treatment may, however, finally be settled when the results appear this year of a large controlled National Cancer Institute trial in the United States using a cisplatin combination and radiotherapy. ${ }^{10}$

The lessons learnt from squamous cell cancer of the head and neck apply to all the less chemosensitive tumours-and they are not new. Encouraging but premature reports of pilot studies are not a reason for a change in established treatment. ${ }^{1}$ Funding bodies and individual clinicians must be patient; advances in cancer chemotherapy sometimes appear to be slow, but it is realistic to look for a progressive increase 